Communications in Physics, Vol.31, No. 1 (2021), pp. 85-93

DOI:10.15625/0868-3166/15358

\title{
SYNTHESIS OF ZnSe NANOCRYSTALS FOR SOLID-STATE LIGHTING APPLICATIONS
}

\author{
BUI THI THU HIEN ${ }^{1}$, HOANG NHU THANH ${ }^{2}$, TRINH DUC THIEN ${ }^{3}$, PHAM NGUYEN \\ $\mathrm{HAI}^{4}$, TRAN THI KIM CHI ${ }^{1, \dagger}$ \\ ${ }^{1}$ Institute of Materials Science, \\ Vietnam Academy of Science and Technology, 18 Hoang Quoc Viet, Cau Giay, Hanoi, Vietnam \\ ${ }^{2}$ Luong The Vinh College, Vu Ban, Nam Dinh, Vietnam \\ ${ }^{3}$ Hanoi National University, 136 Xuan Thuy, Cau Giay, Hanoi, Vietnam \\ ${ }^{4}$ VNU University of Science, 334 Nguyen Trai, Thanh Xuan, Hanoi, Vietnam \\ E-mail: ${ }^{\dagger}$ chittk@ims.vast.ac.vn
}

Received 11 August 2020

Accepted for publication 5 October 2020

Published 10 January 2021

\begin{abstract}
We report the large-scale synthesis of highly luminescent ZnSe nanocrystals (NCs) by a simple and low-cost hydrothermal method. XRD (X-ray Diffraction) and HR-TEM (High Resolution Transmission Microscopy) characterization studies confirmed the formation of as-synthesized $\mathrm{ZnSe} N \mathrm{Cs}$ in cubic structure. The optical property of ZnSe NCs was tunable via controlling the $\mathrm{Zn:Se}$ molar precursor ratios $(0.5: 1-1.5: 1)$, reaction temperature $\left(150-200^{\circ} \mathrm{C}\right)$, and reaction time (5-30 h). The ZnSe NCs hydrothermally treated at $190^{\circ} \mathrm{C}$ for $20 \mathrm{~h}$ with the $\mathrm{Zn}: \mathrm{Se}$ precursor ratio of 1:1 exhibited the highest photoluminescence quantum yield after the $355 \mathrm{~nm}$ excitation. The current-voltage $(I-V)$ characteristics of the ZnSe NCs show its promising application in the solidstate lighting.
\end{abstract}

Keywords: ZnSe; nanocrystals; hydrothermal; photoluminescence; solid-state lighting.

Classification numbers: 78.67.Bf; 78.55.Et.

\section{INTRODUCTION}

In recent years, nanocrystals (NCs) have generated a great deal of attention because of their size-tunable properties thanks to quantum confinement effects [1-8]. The synthesis and characterization of II-VI semiconductor NCs have been the subjects of extensive research due to their outstanding potential in optoelectronic applications such as light-emitting diodes (LEDs),

(C)2021 Vietnam Academy of Science and Technology 
solar cells, sensors, and optical recording materials [9-18]. Among the II-VI semiconductor NCs, cadmium compounds ( $\mathrm{CdS}, \mathrm{CdSe}, \mathrm{CdTe}$, etc.) were widely studied. These materials have so far been the most studied nanocrystal colloid systems. With the controlled growth of particles with diameter between 1.5 and $12 \mathrm{~nm}$, their size-dependent absorption edge covers the entire visible spectra. However, preparation of such small nanocrystals having edges in the UV-blue still remains a challenging task. In addition, these nanocrystals exhibit relatively low quantum yield and broad emission [19-21]. This limits them in the blue and justifies development of other materials such as $\mathrm{ZnSe}$. ZnSe has been reported as an intrinsic semiconductor with a band gap of $2.70 \mathrm{eV}$ and exhibits a strong luminescence in the blue region, making it a promising material for use in optoelectronic devices, including blue laser diodes, light-emitting diodes (LEDs), and photodetectors [22-26]. This material has also been proposed as a good candidate for biomedical labelling $[11,26]$, as well as for use in other active regions of advanced optoelectronic devices [2225, 27-29].

ZnSe NCs have been synthesized by different methods, including microwave-irradiation [30], reverse micelle [31], thermal evaporation [32], solvothermal or hydrothermal method [33,34], and molecular beam epitaxy [35]. Among these synthesis techniques, the hydrothermal method has been extensively used for preparation of a wide range of nanostructures due to its advantages of low temperature reaction, simple equipment, and less consumption of energy [36].

In this paper, we report on the synthesis and characterization of hydrothermally synthesized ZnSe NCs. The influences of the synthesis parameters on the structure and optical characteristics of the obtained QDs were systematically investigated. The highest quality ZnSe NCs were achieved when the $\mathrm{Zn}$ :Se molar ratio was $1: 1$ and the reaction occurred at $190^{\circ} \mathrm{C}$ for 20 hours. Our study shows the perspective for a large-scale, low-cost synthesis of $\mathrm{ZnSe} \mathrm{NCs} \mathrm{for} \mathrm{applications} \mathrm{in}$ solid-state lighting and photovoltaic devices.

\section{EXPERIMENT}

\section{Chemicals}

All the chemical reagents used in our experiments were of analytical grade and used as received without any further purification: Zinc powder and selenium powder were purchased from Sigma-Aldrich while sodium hydroxide and absolute ethanol were purchased from Merck.

\section{Synthesis of ZnSe NCs}

$\mathrm{ZnSe} \mathrm{NCs} \mathrm{were} \mathrm{prepared} \mathrm{according} \mathrm{to} \mathrm{our} \mathrm{previously} \mathrm{reported} \mathrm{procedure} \mathrm{for} \mathrm{ZnSe} \mathrm{NCs} \mathrm{[37].}$ Selenium (Se) and zinc ( $\mathrm{Zn}$ ) powders were directly used as the starting materials. The molar ratios of $\mathrm{Zn}: \mathrm{Se}$ were varied from $0.5: 1$ to $1.5: 1$.

Firstly, $\mathrm{Zn}$ and Se powders were mixed together in a Teflon autoclave (100 ml volume). Then $70 \mathrm{ml}$ of $\mathrm{NaOH}$ was poured into this Teflon (70\% of its total capacity). The suspension solution was sealed immediately in the autoclave and soaked at $190^{\circ} \mathrm{C}$ for 5 hours to 30 hours. After maintaining at this temperature, the autoclave was cooled down to room temperature. The obtained products were $\mathrm{ZnSe}$ colloidal solutions. The washing step was done by slowly adding absolute ethanol, followed by centrifugation at $5500 \mathrm{round} / \mathrm{min}$ for $15 \mathrm{mins}$. The solution was decanted to obtain the precipitate. The samples were finally dried at $80^{\circ} \mathrm{C}$ for 2 hours. The obtained $\mathrm{ZnSe}$ powders were light yellow greenish. 


\section{Characterization}

The structures of the obtained samples were investigated by X-ray diffraction (XRD, D8 ADVANCE) and Raman scattering (LabRam HR Evolution with 532-nm laser excitation). Morphology of NCs and their atomic facets could be observed by a high resolution transmission electron microscope (JEM 2100, JEOL). The photoluminescent signal was collected by a 150 -grating monochromator (Horiba iHR550) and then detected by a thermoelectrically cooled Si-CCD camera (Synapse) in order to characterize our ZnSe NCs optical properties. The absorption spectra were studied by UV-vis Spectrophotometer (Varian Carry 5000).

\section{RESULTS AND DISCUSSION}

ZnSe NCs were synthesized according to the procedure described elsewhere [37] with some modifications: the $\mathrm{Zn}: \mathrm{Se}$ molar ratio of $1: 1$, growth time of 20 hours and the reaction temperature of $190^{\circ} \mathrm{C}$. Fig. 1 presents the XRD pattern of the obtained $\mathrm{ZnSe}$ powder. The distinct diffraction peaks at the angle $2 \theta$ of $27.22^{\circ}, 45.19^{\circ}, 53.56^{\circ}$, $65.83^{\circ}, 72.62^{\circ}$, and $83.44^{\circ}$ could be indexed to (111), (220), (311), (400), (331) and (422) diffraction planes, respectively. All diffraction peaks match well with the standard data for ZnSe (JCPDS/PDF card No. 00-0371463), indicating that the $\mathrm{ZnSe}$ powder is in a cubic phase, similar to those published in the literature for $\mathrm{ZnSe} N C s$ [23, 37, 38]. The surface morphology of the as-prepared $\mathrm{ZnSe}$ NCs was studied by high-magnified TEM images obtained by the HR-

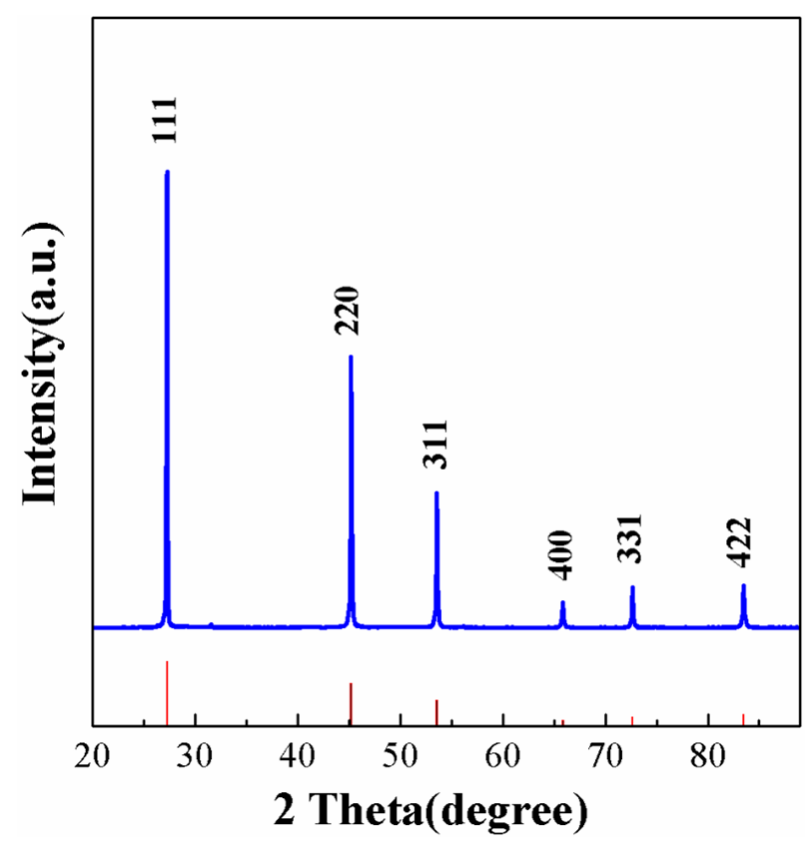

Fig. 1. XRD pattern of $\mathrm{ZnSe} \mathrm{NCs}$ with the $\mathrm{Zn}:$ Se molar ratio of 1:1.

TEM as observed in Fig. 2. The shapes of the ZnSe NCs are varied from sphere to square with the mean size of about $100 \mathrm{~mm}$, which is in good agreement with the value calculated from the XRD pattern using the Scherrer equation $[39,40]$. The size of the $\mathrm{ZnSe}$ NCs estimated from the Debye-Scherrer formula is about $90 \mathrm{~nm}$ (calculated for diffraction peaks at the angle $2 \theta$ of $27.22^{\circ}$ ).

In order to study the structure of the sample in detail, high resolution transmission electron microscope (HR-TEM) measurements were performed. Fig. 2 presents the HR-TEM image of prepared $\mathrm{ZnSe}$ NCs and their SAED pattern inset. We calculated the interplanar spacing to be about $0.3 \mathrm{~nm}$, which corresponds to the (111) plane of cubic ZnSe. The HR-TEM image depicts the clear view of lattice planes and the inset shows their diffraction information of sample (the 

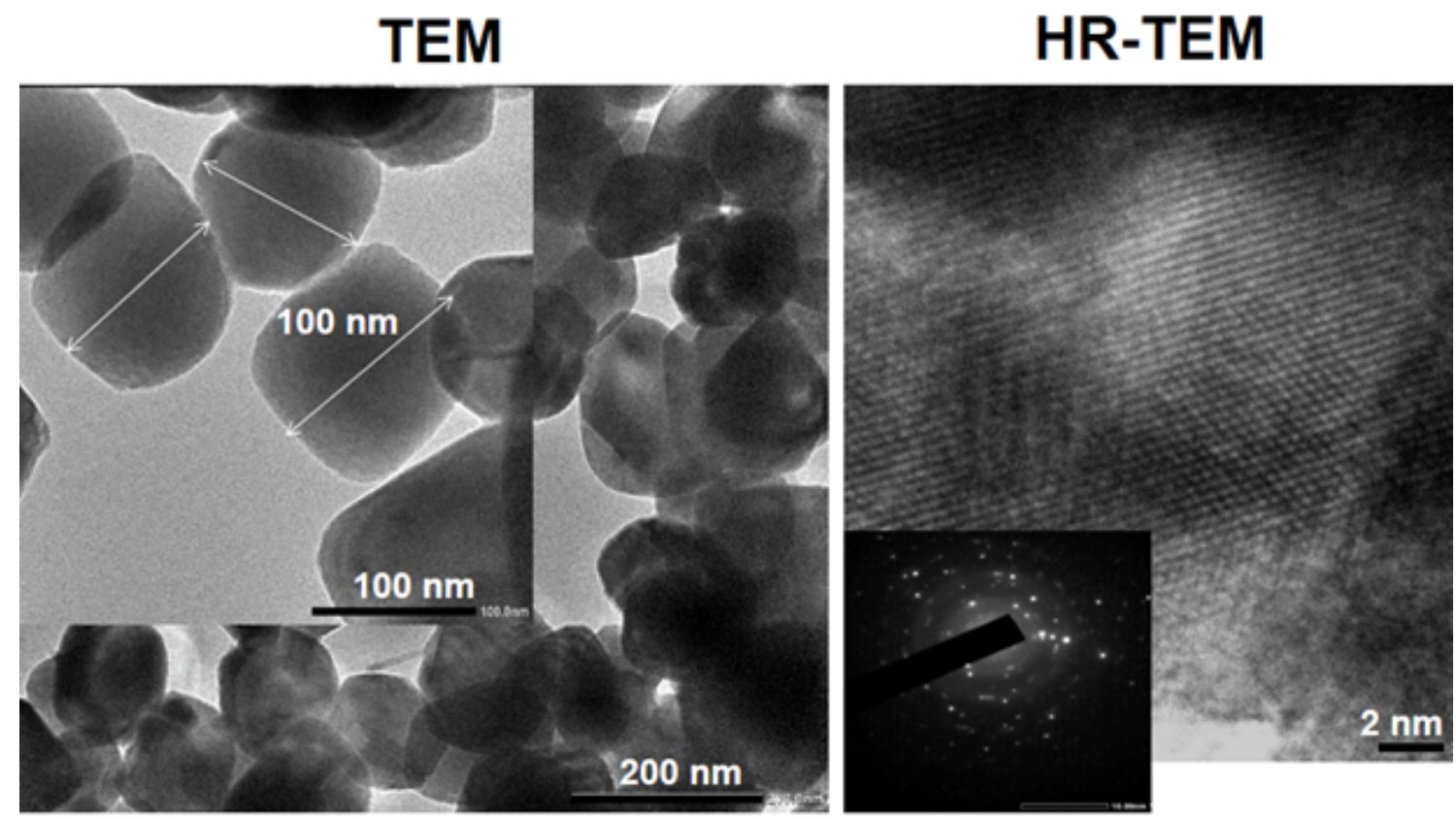

Fig. 2. TEM, HR-TEM images and SA-ED pattern of ZnSe NCs with the Zn:Se molar ratio of 1:1. The scale bar is $2 \mathrm{~nm}$.
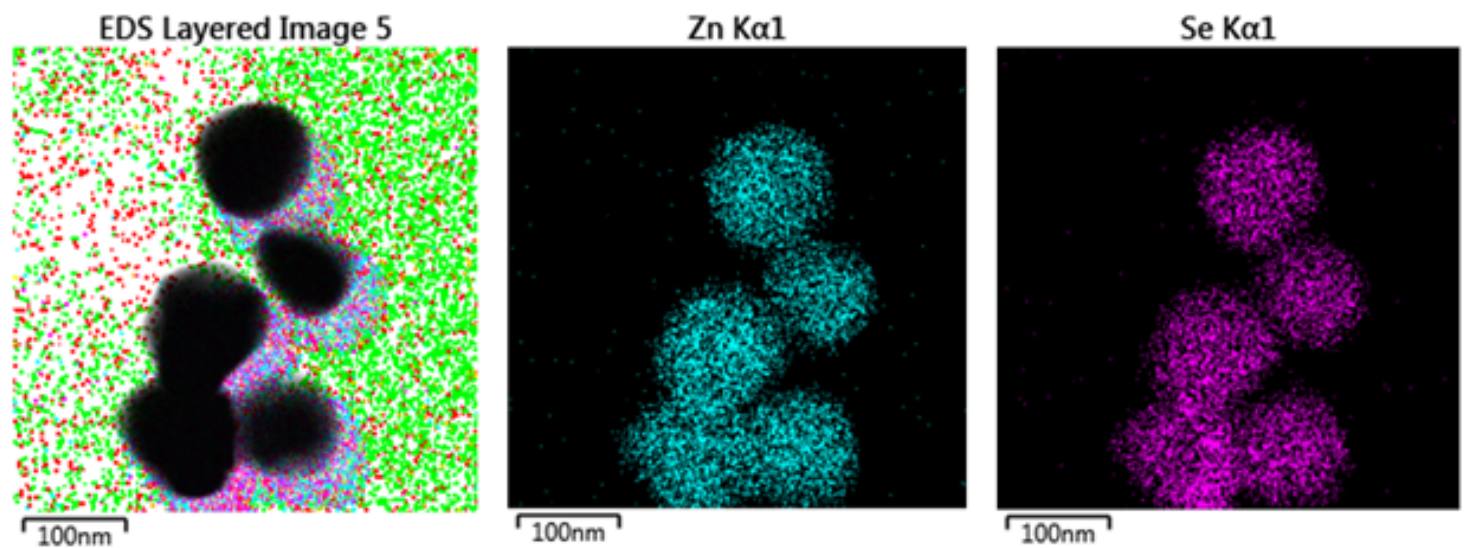

Fig. 3. STEM-mapping images of ZnSe NCs with the Zn:Se molar ratio of 1:1.

pattern consists of diffraction dots that are randomly distributed), confirming the good crystalline structure of the synthesized $\mathrm{ZnSe}$ NCs. Moreover, the elemental composition was determined in STEM-mapping images of ZnSe NCs (Fig. 3), indicating the existence of Zn and Se without the presence of other elements. 
The influences of different synthesis conditions on the formation and quality of ZnSe NCs will be investigated in the following. It is well known that in the synthesis of NCs, the molar ratios of precursors, the growth temperature, and reaction time are the important factors to determine the structural quality and optical properties of the final products [41-43]. In this work, the effect of the reaction temperature was investigated by changing the reaction temperature from $150^{\circ} \mathrm{C}$ to $200^{\circ} \mathrm{C}$ while maintaining the duration of growth time of 20 hours and the same $\mathrm{Zn}$ :Se molar ratio of 1:1. The XRD patterns taken from all the synthesized samples indicate that the $\mathrm{ZnSe}$ NCs have the good crystalline structure as shown above. To determine the effect of the growth duration time, the various syntheses of ZnSe NCs were carried out at the same reaction temperature of $190^{\circ} \mathrm{C}$ for different times between 5 and 30 hours. The experiments revealed that the particle size of NCs became bigger with increasing growth duration time. NCs prepared for 20 hours are the most uniform and stable. In order to study the influence of the molar ratios of the precursors on the quality of $\mathrm{ZnSe} \mathrm{NCs}$ product, we employed the Raman spectroscopy as this technique is considered to be a powerful tool to study the microstructure $[44,45]$ through the lattice vibrations which are related to the local crystalline imperfections or non-stoichiometry in the structures. Fig. 4 shows Raman spectra of synthesized ZnSe NCs with different $\mathrm{Zn}: \mathrm{Se}$ molar ratios $(0.5: 1 \div 1.5: 1)$. Raman diffraction peaks were observed at $138 \mathrm{~cm}^{-1}$, $203 \mathrm{~cm}^{-1}$ and $250 \mathrm{~cm}^{-1}$, corresponding to 2TA, TO and LO phonon modes respectively [46-48]. The absence of Raman mode at $290 \mathrm{~cm}^{-1}$ may be related to lattice defects [48]. The coexistence of TO and LO modes prove good quality of the synthesized ZnSe NPs, which is in accordance with the results obtained from the above XRD and HR-TEM studies. The quality of luminescence materials, besides their

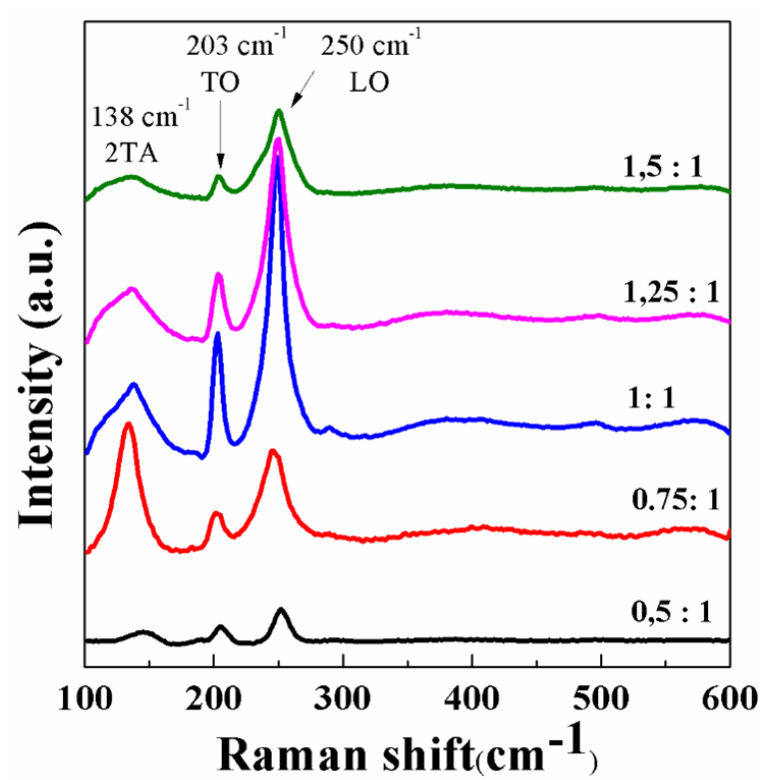

Fig. 4. Raman spectra of ZnSe NCs with different $\mathrm{Zn}: \mathrm{Se}$ molar ratios.

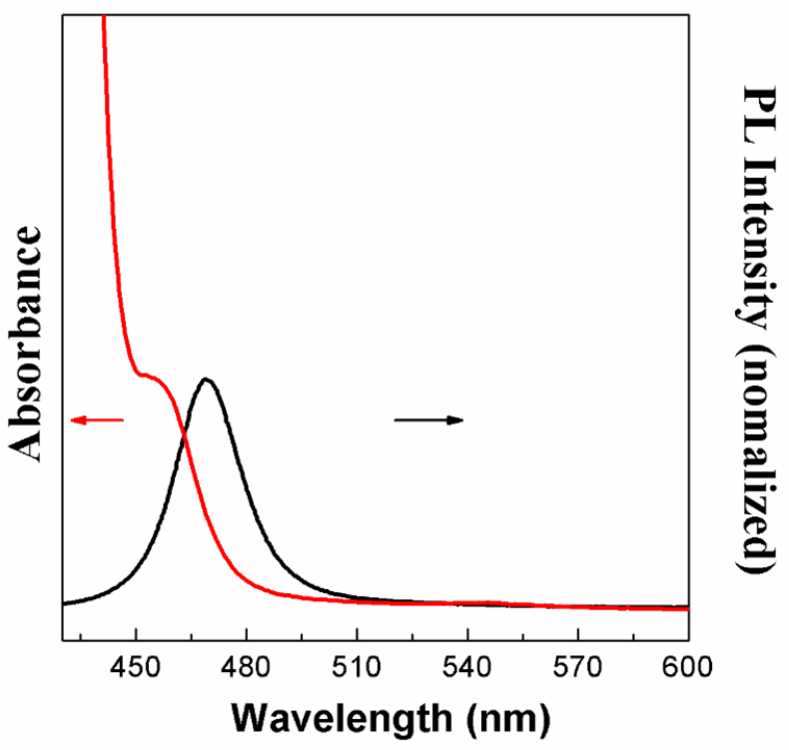

Fig. 5. Absorbance and PL spectra of ZnSe NCs reacted at $190^{\circ} \mathrm{C}$ for 20 hours with the $\mathrm{Zn}: \mathrm{Se}$ molar ratio of 1:1. 
crystalline structure, could be determined by their optical properties. Fig. 5 presents the absorption and PL spectra of ZnSe NCs synthesized at the reaction temperature of $190^{\circ} \mathrm{C}$ for 20 hours, with the $\mathrm{Zn}$ :Se molar ratio of 1:1. The sample is excited by a $355 \mathrm{~nm}$ laser. The obtained $\mathrm{ZnSe} \mathrm{NCs}$ emitted strong blue light at $470 \mathrm{~nm}$ with a small full width at half maximum (FWHM) of $16 \mathrm{~nm}$, which is very promising property for further applications in solid-state lighting.

Table 1. Report about synthesis methods and selected properties of ZnSe NCs.

\begin{tabular}{|c|c|c|c|c|c|c|}
\hline Origin & Method & Precursor & Solvent & Ligand & Shape, size & $\begin{array}{l}\text { Photolumines- } \\
\text { cence } \\
\text { (PL) }\end{array}$ \\
\hline $\begin{array}{l}\text { This } \\
\text { work }\end{array}$ & $\begin{array}{c}\text { Hydrothermal } \\
\left(120-190^{\circ} \mathrm{C}\right. \\
5-20 \mathrm{~h})\end{array}$ & $\begin{array}{c}\mathrm{Zn}, \mathrm{Se} \\
\text { powders }\end{array}$ & $\mathrm{NaOH}$ & - & $\begin{array}{c}\text { Sphere } \\
(50-500) \\
n m\end{array}$ & $\begin{array}{c}\text { Strong }(470 \mathrm{~nm}, \\
F W H M=16 \\
n m)\end{array}$ \\
\hline Ref. [49] & $\begin{array}{c}\text { Hydrothermal } \\
\left(40-180^{\circ} \mathrm{C},\right. \\
2-10 \mathrm{~h})\end{array}$ & $\begin{array}{c}\text { Zinc } \\
\text { acetate, } \\
\text { Sodium } \\
\text { selenite } \\
\text { anhy- } \\
\text { drous }\end{array}$ & $\begin{array}{c}\mathrm{NaOH} \\
\mathrm{N}_{2} \mathrm{H}_{4} \cdot \mathrm{H}_{2} \mathrm{O}\end{array}$ & CTAB & $\begin{array}{c}\text { Sphere } \\
(200-400) \\
\mathrm{nm}\end{array}$ & N.G. \\
\hline Ref. [50] & $\begin{array}{c}\text { Reverse } \\
\text { Microemulsion } \\
\text { (RT, } \\
\text { oxygen-free by } \\
\text { nitrogen) }\end{array}$ & $\begin{array}{l}\text { Zinc } \\
\text { acetate, } \\
\text { Se } \\
\text { powder, }\end{array}$ & $\begin{array}{c}\text { Cyclohexane, } \\
\mathrm{NaBH}_{4}\end{array}$ & $\begin{array}{c}\text { Triton } \\
X- \\
100 / 2- \\
\text { propanol }\end{array}$ & $\begin{array}{c}\text { Sphere } \\
(2.8-14.5) \\
\mathrm{nm}\end{array}$ & $\begin{array}{c}\text { Strong } \\
(386-426 \mathrm{~nm} \\
\text { FWHM = } 80 \\
\mathrm{~nm})\end{array}$ \\
\hline Ref. [51] & $\begin{array}{c}\text { Thermal } \\
\text { treatment } \\
\left(450-700^{\circ} \mathrm{C}\right)\end{array}$ & $\begin{array}{l}\text { Zinc } \\
\text { nitrate, } \\
\text { Se } \\
\text { powder }\end{array}$ & $\begin{array}{c}\text { PVP, } \\
\text { Ethylenediam } \\
\text { ine }\end{array}$ & - & $\begin{array}{c}\text { N.G. } \\
(7-18) \mathrm{nm}\end{array}$ & N.G. \\
\hline Ref. [52] & $\begin{array}{l}\text { Microwave } \\
\text { irradiation } \\
\left(10^{-6} \text { torr }\right)\end{array}$ & $\begin{array}{l}\mathrm{Zn} \\
\text { powder, } \\
\text { Se } \\
\text { powder }\end{array}$ & - & - & $\begin{array}{l}\text { Sphere } \\
(50) \mathrm{nm}\end{array}$ & $\begin{array}{c}\text { Weak } \\
(401 \mathrm{~nm}, \\
\text { FWHM = 50 } \\
\mathrm{nm})\end{array}$ \\
\hline Ref. [53] & $\begin{array}{c}\text { Hydrothermal } \\
\left(180^{\circ} \mathrm{C}, 12 \mathrm{~h}\right)\end{array}$ & \begin{tabular}{|c} 
Zinc \\
substrates, \\
Se \\
powder
\end{tabular} & $\begin{array}{c}\mathrm{N}_{2} \mathrm{H}_{4} \cdot \mathrm{H}_{2} \mathrm{O} \\
\mathrm{NaOH}\end{array}$ & - & Nanowall & N.G. \\
\hline Ref. [54] & $\begin{array}{c}\text { Co- } \\
\text { precipitation } \\
(8 \mathrm{~h})\end{array}$ & $\begin{array}{c}\text { Zinc } \\
\text { chloride, } \\
\text { Sodium } \\
\text { selenide }\end{array}$ & $\begin{array}{l}\mathrm{N}_{2} \mathrm{H}_{4} \cdot \mathrm{H}_{2} \mathrm{O} \\
\text { ethylene } \\
\text { glycol, PVP }\end{array}$ & - & $(20-30) \mathrm{nm}$ & Weak \\
\hline Ref. [55] & $\begin{array}{c}\text { Anisotropic } \\
\text { growth } \\
\left(240^{\circ} \mathrm{C}, \mathrm{Ar} \text { air }\right)\end{array}$ & $\begin{array}{c}\text { Zinc } \\
\text { acetate, } \\
\text { Selenium }\end{array}$ & $\begin{array}{l}\text { Oleylamine, } \\
\text { octadecene }\end{array}$ & - & $\begin{array}{c}\text { Nanorod } \\
\text { (Length: } \\
\text { 5-9 nm, d = } \\
2.8 \text { ) }\end{array}$ & $\begin{array}{c}\text { Strong (396 nm, } \\
\text { FWHM }=20 \\
n m)\end{array}$ \\
\hline
\end{tabular}


Table 1 shows synthesis methods and selected sample properties of $\mathrm{ZnSe}$ NCs which are extracted from previous studies. Comparing with those publications, our obtained ZnSe samples were synthesized by simple and low-cost method, with fewer chemicals and less equipment, largescale of production, and high photoluminescence quantum yield. Moreover, this can be considered as a clean chemical method because the experiment is carried out completely in a closed container. Especially, ZnSe NCs emit strong blue light, promise to be a potential candidate in optoelectronics field, solid-state lighting. To illustrate this capability, we carried out the fabrication of the electronic structure as shown in the inset of Fig. 6 (its details will be presented in the other article) and measured current-voltage (I-V) characteristics. The results of the I-V characteristics of the ZnSe NCs in the built electronic structure show a diode characteristic, which was expectedly used in solid-state lighting and optoelectronic devices.

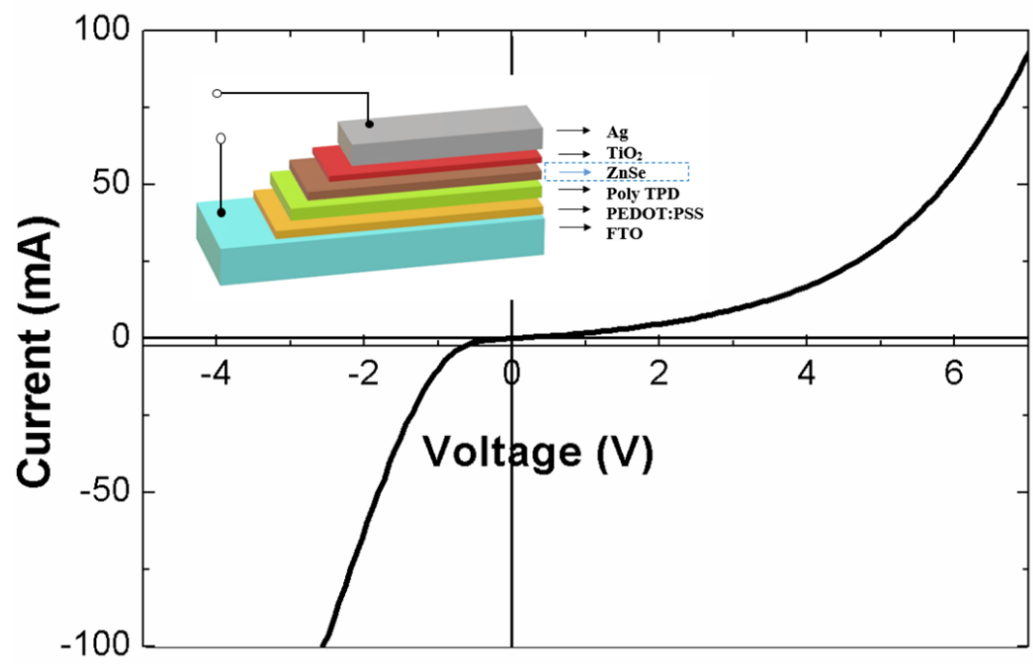

Fig. 6. Current-voltage (I-V) characteristics of the ZnSe NCs.

\section{CONCLUSION}

The ZnSe NCs were successfully synthesized by the hydrothermal method, using zinc and selene powders as precursors. The NCs with a 1:1 Zn:Se molar ratio reacted at $190^{\circ} \mathrm{C}$ for 20 hours were found to show the highest quality. This optimal nanomaterial possesses the high crystal quality and luminescence efficiency, emitting the strong blue light $(470 \mathrm{~nm})$, which is desirable for applications in solid-state lighting. The current-voltage (I-V) characteristics of the ZnSe shows its application in solid-state lighting and optoelectronic devices.

\section{ACKNOWLEDGEMENTS}

This work was supported by the NAFOSTED (Code: 103.03-2017.363). We thank the National Key Laboratory for Electronic Materials and Devices (VAST/IMS) for the use of facilities. 


\section{REFERENCES}

[1] G. M. Dalpian and J. R. Chelikowsky, Phys. Rev. Lett. 96 (2006) 226802.

[2] El-Hussein D. Helal, Hassan A. Dessouki, Mostafa Y. Nassar and Ibrahim S. Ahmed, Journal of Basic and Environmental Sciences. 5 (2018) 20.

[3] M. A. Malik, N. Revaprasadu and P. O. Brien, Chem. Mater. 13 (2001) 913.

[4] A. Miyawaki, Dev. Cel. 4 (2003) 295.

[5] W.C.W. Chan, S. Nie, Science. 281 (1998) 2016.

[6] A. P. Alivisatos, Nat. Biotechnol. 22 (2004) 47.

[7] W.J. Parak, D. Gerion, T. Pellegrino, D. Zanchet, C. Micheel, S. C. Williams, R. Boudreau, M. A. Le Gros, C. A. Larabell, A. P. Alivisatos, Nanotechnology 14 (2003) R15.

[8] C. M. Niemeyer, Angew. Chem. In. Edn. 40, (2001) 4128.

[9] A. Hines and P. Guyot-Sionnest, J. Phys. Chem. 100 (1996) 468.

[10] J. Yang, J.-H. Zeng, S.-H. Yu, L. Yang, G.-E. Zhou, Y.-T. Qian, Chem. Mater. 12 (2000) 3259.

[11] Narayan Pradhan, David M. Battaglia, Yongcheng Liu and Xiaogang Peng, Nano Letters. 7 (2007) 317.

[12] L. Yang, R. Xie, L. Liu, D. Xiao and J. Zhu, J. Phys. Chem. 115 (2011) 19507.

[13] L. Yang, J. Zhu and D. Xiao, RSC Adv. 2 (2012) 8179.

[14] A. Shavel, N. Gaponik and A. Eychmuller, J. Phys. Chem. B. 108 (2004) 5905.

[15] X. Fang, S. Xiong, T. Zhai, Y. Bando, M. Liao, U.K. Gautam, Y. Koide, X. Zhang, Y. Qian and D. Golberg, Adv. Mater. 21 (2009) 5016.

[16] N. Pradhan and X. G. Peng, J. Am. Chem. Soc. 129 (2007) 3339.

[17] S. M. Emin, N. Sogoshi, S. Nakabayashi, T. Fujihara and C. D. Dushkin, J. Phys. Chem. C. 113 (2009) 3998.

[18] R. Zeng, T. Zhang, G. Dais and B. Zou, J. Phys. Chem. C. 115 (2011) 3005.

[19] Z. A. Peng, X. Peng, J. Am. Chem. Soc. 123 (2001) 183.

[20] A. L. Rogach, T. Franzl, T. A. Klar, J. Feldmann, N. Gaponik, V. Lesnyak, A. Shavel, A. Eychmüller, Y. P. Rakovich, J. F. Donegan, J. Phys. Chem. C. 111 (2007) 14628.

[21] Soodabe Gharibe, Shahrara Afshar and Leila Vafayi, Chem. Soc. Ethiop. 28 (2014) 37.

[22] Satyajit Saha, Tapan Kumar Das and Rahul Bhattacharya, International Journal of Research in Applied, Natural and Social Sciences. 4 (2016) 1.

[23] Aeshah Salem, Elias Saion, Naif Mohammed Al-Hada, Halimah Mohamed Kamari, Abdul Halim Shaari and Shahidan Bin Radiman, Results in Physics 7 (2017) 1556.

[24] Colli A, Hofmann S, Ferrari A, Ducati C, Martelli F, Rubini S, Cabrini S, Franciosi A, Robertson J, Appl. Phys. Lett. 86 (2005) 153103.

[25] Haiyan Hao, Xi Yao and Minqiang Wang, Optical Materials. 29 (2007) 573.

[26] H. Qian, L. Li, J. Ren, J. Mater. Res. Bull. 40 (2005) 1726.

[27] A. Jafar Ahamed, K. Ramar and P. Vijaya Kumar, Journal of Nanoscience and Technology 2 (2016) 148.

[28] Pei Xie, Shaolin Xue, Youya Wang, Zhiyong Gao, Hange Feng, Lingwei Li, Dajun Wu, Lianwei Wang and Paul K. Chu, RSC Adv. 7 (2017) 10631.

[29] Juliana J. Andrade, Aluízio G. Brasil Juniorac, Breno J. A. P. Barbosa, Clayton A. Azevedo Filhoac, Elisa S. Leitead, Patrícia M. A. Fariasae, Adriana Fontesae, Beate S. Santosac, Proc. of SPIE. 7575 (2010) 757507.

[30] L. Huang, H. Han, Mater. Lett. 64 (2010) 1099.

[31] F. T. Quinlan, J. Kuther, W. Tremel, W. Knoll, S.Risbud and P. Stroeve, Langmuir. 16 (2000) 4049.

[32] Z. D. Hu, X. F. Duan, M. Gao, Q. Chen, L. M. Peng, J. Phys. Chem. C. 111 (2007) 2987.

[33] Z. X. Deng, C. Wang, X. M. Sun, Y. D. Li, Inorg. Chem. 41 (2002) 869.

[34] Y. D. Li, Y. Ding, Y. T. Qian, Y. Zhang, L. Yang, Inorg. Chem. 37 (1998) 2844.

[35] Y. G. Wang, B.S. Zhou, T. H. Wang, N. Wang, Y. Cai, Y.F. Chan, S.X. Zhou, Nanotechnology 17 (2006) 2420.

[36] Fakhrurrazi Ashari, Josephine Liew Ying Chyi, Zainal Abidin Talib, W. Wahmood Wan Yunus, Leong Yong Jian, Lee Han Kee, Chang Fu Dee \& Burhanuddin Yeo Majlis, Sains Malaysiana 45 (2016) 1191.

[37] Tran Thi Kim Chi, Vu Thi Phuong Thuy, Bui Thi Thu Hien and Nguyen Quang Liem, Vietnam Journal of Chemistry, 553e12 (2017) 120.

[38] Minqiang Wang, Xiao Huo, Jianping Li,Zhonghai Lin and Xi Yao, Ceramics International 34 (2008) 1081. 
[39] Bo Feng, Jian Cao, Donglai Han, Shuo Yang and Jinghai Yang, Journal of Materials Science: Materials in Electronics 26 (2015) 3206.

[40] M. Bedir, M. Oztas, O. F. Bakkaloglu, and R. Ormanci, Eur. Phys. J. B. 45 (2005) 465.

[41] J. Park, S. W. Kim, J. Mater. Chem. 21 (2011) 3745.

[42] H. Zhong, Y. Zhou, M. Ye, Y. He, J. Ye, C. He, C. Yang, Y. Li, Chem. Mater. 20 (2008) 6434.

[43] D. Deng, Y. Chen, J. Cao, J. Tian, Z. Qian, S. Achilefu, Y. Gu, Chem. Mater. 24 (2012) 3029.

[44] N. Q. Liem, G. Sagon, V. X. Quang, H. V. Tan, P. Colomban, J. Raman Spectrosc. 31 (2000) 933.

[45] T. T. K. Chi, G. Gouadec, P. Colomban, G. Wang, L. Mazerolles, N. Q. Liem, J. Raman Spectrosc. 42 (2011) 1007.

[46] GuoweiLu, Huizi An, Yu Chen, Jiehui Huang, Hongzhou Zhang, Bin Xiang, Qing Zhao, Dapeng Yu and Weimin Du, Journal of Crystal Growth 274 (2005) 530.

[47] Lingcong Shi, Chunrui Wang, Jiale Wang, Zebo Fang and Huaizhong Xing, Advances in Materials Physics and Chemistry 6 (2016) 305.

[48] W. Zhou, R. Liu, D. Tang and B. Zou, Nanoscale Res. Lett. 8 (2013) 314.

[49] Hongni Wang and Fanglin Du, Cryst. Res. Technol. 41 (2006) 323

[50] Lin Yang, Ruishi Xie, Lingyun Liu, Dingquan Xiao, and Jianguo Zhu, J. Phys. Chem. C. 115 (2011) 19507

[51] Aeshah Salem, Elias Saion, Naif Mohammed Al-Hada, Halimah Mohamed Kamari, Abdul Halim Shaari, Shahidan Radiman, Results in Physics 7 (2017) 1175.

[52] Mohd. Shakir, Siddhartha, G. Bhagavannarayana, M.A.Wahab, Chalcogenide Letters 8 (2011) 435.

[53] Pei Xie, Shaolin Xue, Youya Wang, Zhiyong Gao, Hange Feng, Lingwei Li, Dajun Wu, Lianwei Wang and Paul K. Chud, RSC Adv. 7 (2017) 10631.

[54] A. Jafar Ahamed, K. Ramar, P. Vijaya Kumar, Journal of Nanoscience and Technology 2 (2016) 148.

[55] Jiajia Ning Stephen V. Kershaw Andrey L. Rogach, Angewandte Chemie International Edition, 595385 (2020). 